Erratum

\title{
Erratum: Perez-Montiel, J.; Manera Erbina, C. Investment Sustained by Consumption: A Linear and Nonlinear Time Series Analysis. Sustainability 2019, 11,4381
}

\author{
Jose Perez-Montiel * (i) and Carles Manera Erbina \\ Department of Applied Economics, University of the Balearic Islands, Palma 07122, Spain \\ * Correspondence: jose.perez@uib.es
}

Received: 28 May 2020; Accepted: 29 May 2020; Published: 29 May 2020

The authors would like to make the following corrections to the published paper [1]. The changes are as follows:

(1) Replacing the reference [47]:

Piotr, F.; Economics, O.W.-A. Undefined 2018, Nonlinear Granger causality between grains and livestock. Agric. Econ. 2018, 7, 328-336.

with

Fiszeder, P.; Orzeszko, W. Nonlinear Granger causality between grains and livestock. Agric. Econ.-Czech 2018, 64, 328-336.

The authors and the Editorial Office would like to apologize for any inconvenience caused to the readers by these changes. The change does not affect the scientific results. The manuscript will be updated, and the original will remain online on the article's webpage.

\section{Reference}

1. Perez-Montiel, J.; Manera Erbina, C. Investment Sustained by Consumption: A Linear and Nonlinear Time Series Analysis. Sustainability 2019, 11, 4381. [CrossRef]

(C) 2020 by the authors. Licensee MDPI, Basel, Switzerland. This article is an open access article distributed under the terms and conditions of the Creative Commons Attribution (CC BY) license (http://creativecommons.org/licenses/by/4.0/). 